\title{
Phenomenology in Pure Aesthetics
}

\author{
Mustapha El Moussaoui \\ Universitat Politecnica de Valencia, Valencia 46071, Spain
}

\begin{abstract}
Theories of aesthetics have represented aesthetic object as a framed, distanced and contemplated individual piece to be appreciated. In particularly to be symbolized as pure, objects of appreciation must be approached with complete objectivity regardless of its function. In architecture, "purity" can be understood as the formal or structural elements visible, or pure of any ornament. But, in the philosophical-aesthetic sense, purity is of "disinterest" manner. Aesthetic concepts and values are "free" and "pure" in the Kantian sense that they are not derived from any priori grounds. This vision has been challenged by environmental and everyday aesthetics, in which they bring everyday environments and matters into consideration as possible objects of aesthetic appreciation. In this paper, I will discuss the importance of aesthetics in the dwelling sense and whether aesthetics is a matter of value in the reminiscent memory of the dweller. Moreover, question the ambiguous term "pure" in architecture and whether this term is correct in the dwellers sense.
\end{abstract}

Key words: Aesthetics, dwelling, Heidegger, purity, architecture.

\section{Introduction}

In the 18 th century theories of aesthetics started gaining throttle in the philosophical circle. Aesthetic theorists represented pure aesthetics as a framed, distanced, and contemplated individual piece to be appreciated. In order for an object to be annotated as pure, objects of appreciation must be approached with complete objectivity regardless of its function.

In architecture, "purity" can be understood as visible structural elements (honesty), or pure of any ornament. But, in the philosophical-aesthetic sense, purity is of "disinterest" manner. Aesthetic concepts and values are "free" and "pure" in the Kantian sense that they are not derived from any priori grounds. Another understanding can be comprehended to the "Pure Architecture" that the designed object is kept to its original idea, untouched by the client, or kept to its original functionality. On the other hand, architecture has been always linked to function or else it would be categorized as a sculpture. Therefore, it was concluded by Fenner [1] that, as architecture is essentially associated with function, then there can be

Corresponding author: Mustapha El Moussaoui, doctorate of architecture, research field: architecture theory. no such thing as pure architecture, if we are considering it through the aesthetic purity discourse.

"Taking disinterest as the model of aesthetic purity is sound. Taking the pure approach to attendance to works of architecture is unsound. Aesthetic reductionism fails as a rewarding approach to most works of art, but it is entirely wrong-headed as an approach to works of architecture. Works of architecture are richly functional, richly contextual, and they reward attendance through a plurality of sensory modalities".

As we can see, the term "pure" is ambiguous in its use, the term itself can be used in many altered ways, but if we are looking in specific to architecture aesthetics, we must divert our attention to the "pure" sense in architecture. In this paper, we will dig into the essence of architecture or the dwelling phenomena, understand the basic human need of shelter, which will lead us to understand architecture in its purest form. Besides, we will account a study on some dwelling spaces, studied in Eastern Bekaa Valley, Lebanon, which is an area that only recently has witnessed new construction materials and methods. The spaces studied-whether interior or exterior-where created out of a necessity to sustain 
their living habits in an environmentally harsh region.

In a relation between aesthetics, real phenomenological experience, and an existential need, we will identify our results and check if we are able to give a new understanding to the word "pure", in which, it would be more intact with the dwelling aesthetic rather than a general aesthetic discourse used on all objects of aesthetic quality. Hence, a terminology can be applied more conveniently in the architecture domain rather that borrowing terminologies that do not apply in the architectural realm.

\section{Purity}

Purity, as we have mentioned is an ambiguous term, that has been used differently through different cultures, but in order to understand it better we must look at its origins. To reach a better understanding of the word we had to dig into the etymology of the word use. Purity is a terminology that can be understood and used in many fields, varying from religious spheres, philosophy, household, etc. In every domain the word "pure" can refer to something specific in that realm. Purity in its etymological form, comes from the Latin Purus, which derives from the Greek pyr/pur (fire, $\pi v ́ \rho$; gen: puros), as initially fire was used for cleansing. Nonetheless, Heraclitus ${ }^{1}$-a pre-Socratic philosopher-identified fire as the main element of creation, as it is the primary element for all changes. Fire was one of the archaic proposed by the Pre-Socratics, most of whom sought to reduce the cosmos, or its creation, to a single substance. Heraclitus considered fire to be the most fundamental of all elements, purifying and nurturing all the other elements, thus uncovering all the outer shells reaching its pure essence [2].

In its current use, purity can mean: virtue, lack of corruption, honesty, cleanness, clearness, clarity, etc. But to an architect, pure architecture can mean several

\footnotetext{
${ }^{1}$ A pre-Socratic philosopher $540 \mathrm{BC}-480 \mathrm{BC}$ or the weeping philosopher demonstrated that fire is the most important element of the universe and as life is changing fire also changes things.
}

things; a building that has not been modified or changed since the architect's primary idea and design, or the honest architecture that shows the structure without hiding them, in which it means keeping the materials and joints honest to their physical elements. Moreover, it can also mean a white building, free and pure of all ornaments as Adolf $\operatorname{Loos}^{2}$ puts it in his Ornament \& Crime ${ }^{3}$.

In aesthetic philosophy, it is divided into two parts: aesthetic object and aesthetic experience. In the former, aesthetic object, it can be understood as the demonstration of the essence of an object. Whereas, in the later, for an aesthetic experience to be pure, it must be approached by the attender without any former interest, the attention of the attender must be absolute, or the notion of "disinterestedness". This dualistic approach is a birth of Kant's objective/subjective split in his Critique of Pure Reasoning, in which he explains, in order to reach the pure a priori, one must get rid of all the subjective posteriori reasoning.

"Intuitions and conceptions, constitute all elements of our knowledge, both are either pure or empirical. They are empirical when sensation is contained in them, pure when no sensation is mixed with the representation. Sensation we may call the matter of sensuous cognition. Pure intuition consequently contains merely the form under which something is intuition, and pure conception only the form of the thought of an object" [3].

\section{Dwelling Phenomenon}

The concept of dwelling is one of the most recurrent terms in the architecture studies of all time. Dwelling is the act of inhabiting a space, but not merely a physical matter, but rather an existential

\footnotetext{
2 An architect and theoretician born in Vienna 1860-1939, one of the pioneers of the modernist movement, hated the fake, fussy, and decorated elements. Loos, preferred clean, simple, and stripped-down architecture.

${ }^{3}$ See Loos, A. 2019. Ornament and Crime: thoughts on design and materials, s.l.: PENGUIN Books. For an in-depth understanding of modern pure architecture. Originally published in 1913.
} 
relief to our existence. One of the most prominent philosophers to bring up the notion of "Dwelling" in its philosophical approach is Martin Heidegger. Heidegger's "Building Dwelling and Thinking" 4 considered to be one of the most influential texts in the 20th century due to its remarkable interpretation and perspective to architecture and the act of inhabiting a space. Architects of the century were highly influenced by the text. Since the beginning of Heidegger's texts, he makes it noticeable in which part of architecture he wants to grab, as architecture in his point of view is not about the aesthetics nor the technical details only, but architecture is intact to the essence of what it really has to be in its purest form.

In the Heideggerian understanding of dwelling, Heidegger [4] started in his conference "Building Dwelling Thinking" by stating the question "what is it to Dwell"? He questioned the difference between different action areas, whether our working space, or living space. To him it is a matter of perception and space perceiving that we daily deal with. Additionally, Heidegger, claims that one can live in a building daily but not feel home in the building. He mentions that the notions such as "well planned", "easy to keep" and "attractively cheap" were missing the essential function of dwelling. Moreover, he adds that the words "residential" and "housing" imply the new production system over the priorities of human beings. This contemporary relation between building and dwelling suggests an unfavorable comparison between past and present. Heidegger's methodology, was to dig into the etymological essence of a word to be able to reach its essential use. As words created by the need express a specific emotion, he starts by looking into the word dwelling in its etymological study [4].

"Bauen originally means to dwell. Where the word bauen still speaks in its original sense. It also says how far the essence of dwelling reaches. That is bauen, buan, bhu, beo are our word bin in the versions: ich

4 Heidegger, M. 1971. "Building Dwelling Thinking." In Poetry, Language, Thought, trans. by Albert Hofstadter. New York: Harper Colophon Books. bin, I am, du bist you are, the imperative form bis, be. What then does ich bin mean? The old word bauen to which the bin belongs, answers: ich bin, du bist mean I dwell, you dwell. The way in which you are and I am, the manner in which we humans are on the earth, is buan, dwelling [...] The old word bauen which says that man is insofar as he dwells, this word bauen, however also means at the same time to cherish and protect, to preserve and to care for, specifically to till the soil, to cultivate the vine."

Heidegger attempts to demonstrate how the contemporary use of the words transformed its conception and our behavior; building as construction, and dwelling as living. On the other hand, building and dwelling, combined together, are central to the human existence. The existential "I" of which we belong "I am" and "you are", "ich bin", "du bist" means I dwell, you dwell. He is suggesting that building and dwelling sit in the core of existence. Living in a house and cultivating the house is an affirmation of being. Rendering his etymology, when we mention the "I am", "you are", "we are", we are reassuring the great importance of dwelling through human existence.

\subsection{Case Study}

In Eastern Bekaa Valley ${ }^{5}$ dwelling habitats and habits are intensely apparent. People started inhabiting the area since pre-roman era, as in the area itself inhabits several roman ruins, which are considered a UN Heritage, the most famous is Baalbek ruins. The example given by Eastern Bekaa is due to the study made on that specific area. Moreover, it is the hometown of the researcher. On the other hand, results are not inclusively about this area, but it is recurrent on all the lands that humans expressed their existential

\footnotetext{
${ }^{5}$ Bekaa Valley is situated on an altitude between $800 \mathrm{~m}$ and $1,300 \mathrm{~m}$. The mountains from the east and west can go up to an altitude of 3,008 m (Kornet Sawda-western mountain) and 2,800 m (Hermon-Eastern Series). The valley is famous for its farming lands, due to subsidies from both mountains they accommodate in the soil of the Bekaa valley making it extremely rich for cultivation (Fig. 2).
} 
experience. As mentioned, Bekaa Valley is situated between two mountain series, and sits on a height altitude between $800 \mathrm{~m}$ and 1,300 m. Hence, residents had to adapt to the weather with degrees that can vary from -7 degrees in winter to 40 degrees in summer, thus, harsh winters and dry hot summers. On the other hand, the area only recently (1960's) witnessed new construction methodologies and materials, such as steel and concrete. Furthermore, the roads to the area were not as facilitated, as electric cables reached them after 1966.

Architecture in the region was completely made according their own know-how. Local dwellers did not construct under any formal law, or engineering support. They built according to the local know-how material and familiarity, thus, what they learned from their parents, neighbors, and the local masons. Their dwelling houses were built as single room separated from their bathrooms, later, when it is possible (financially), they would add another space to their dwelling spaces.

The houses mostly made of natural stone from the land itself, covered on its interior with mud. The ceilings made of wood covered with straw and mud (Fig. 1). Every year-starting of autumn season-dwellers climb their roofs with a "Kontar" and renew the ceiling cover of mud and straw. Old inhabitants still resonate the smell of the ceiling mud. To sustain their daily lives, dwellers created their own kind of food, which later on, transformed into cultural meals in Lebanon. For example, throughout winter dwellers did not have any source of meat (whether it is weather conditions, or financial means). Henceforth, residents created their own type of meat ${ }^{6}$, milk $^{7}$, and eggplants ${ }^{8}$.

\footnotetext{
6 "Kawarma" is usually made of sheep meat. They dry and cook the meat with fats, and they leave it in jars. Such process would not let the meat to rotten for a long period. They usually start making "Kawarma" at the end of summer.

7 "Keshk" made of dried milk, usually is done on the dwellers' rooftop at the end of summer.

8 "Makdous" made of dried eggplant, filled with nuts, fleifle, olives, etc.
}

Such food-which later developed into cultural cuisines and starters - was made to sustain their lives during winters, keeping them warms, and providing energy. The food created or modified needed a special way of restoration, as there were no fridges. Therefore, specific tectonics created in their interior spaces create a sustainable way for keeping the food warm in winter, and cool in summer (Figs. 4 and 5).

Fig. 2 shows the interior space of a living room, which also was used for food storage. The arch on the right is an entrance to the showering corner. This spatial articulation acts like a mud closet (Fig. 5). It is around 1 meter away from the stone wall and from above, dwellers discharge the specified food in the designated space (Fig. 3). An opening at the bottom of the element is used as a space discharge, usually clotted with a specific piece of cloth (Fig. 3). Mud absorbs the humidity and keeps all stored food cool, while cold air drops from bottom opening and hot air circulates from above.

\subsection{Dwelling Aesthetics}

Norberg-Schulz [5] mentions in his book Towards a

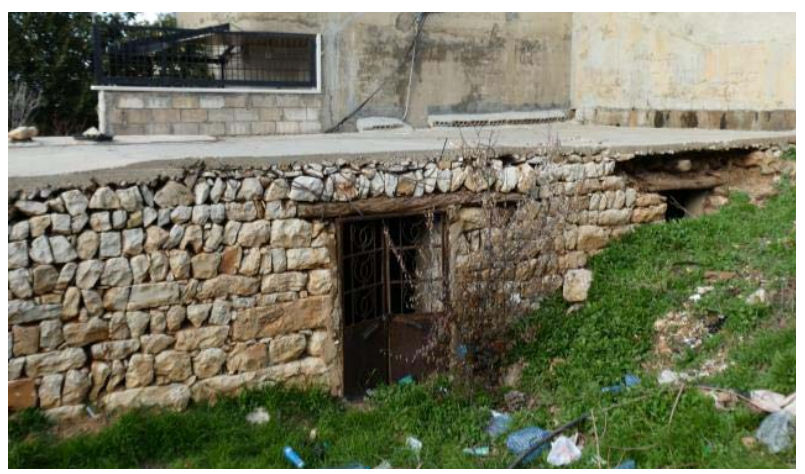

Fig. 1 Bekaa dwelling.

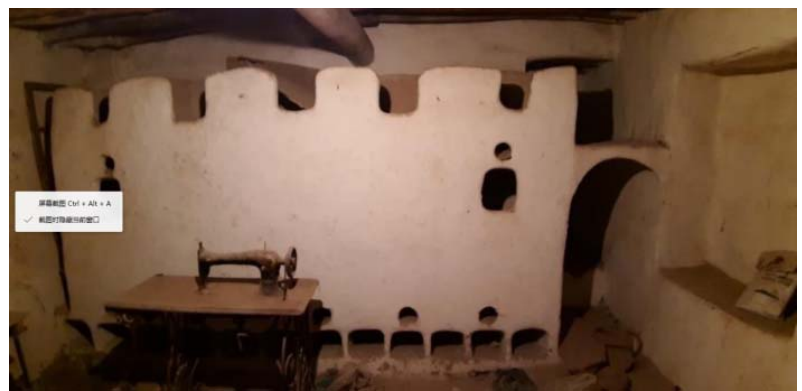

Fig. 2 Interior space articulation. 


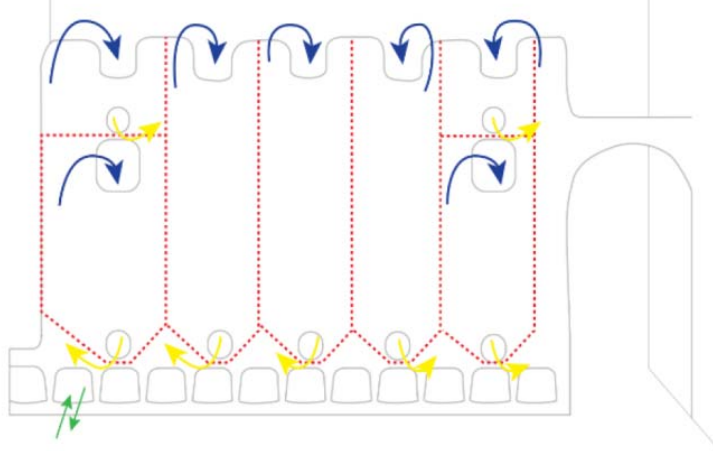

Fig. 3 Usage diagram.

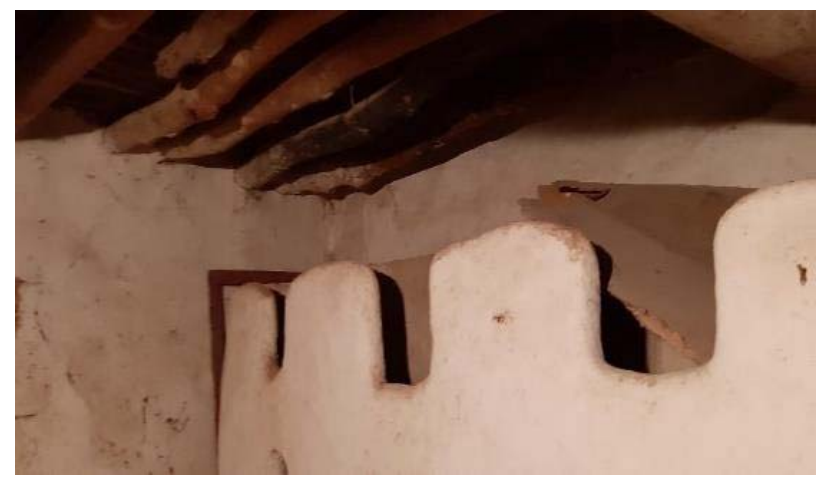

Fig. 4 Food insertion.

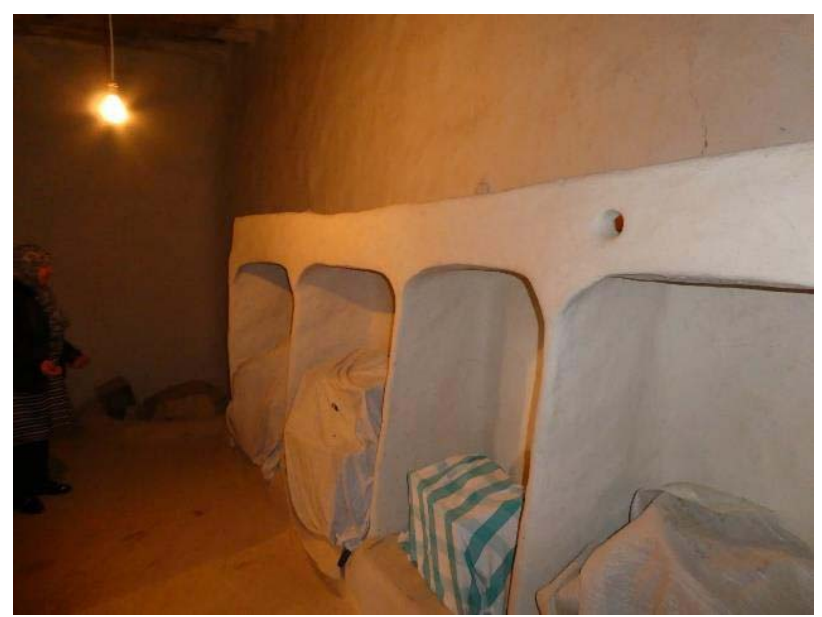

Fig. 5 Space articulation.

Phenomenology of Architecture, that dwelling is synonym of "existential foothold". Moreover, the purpose of architecture in an existential sense is "to dwell", implying it is more than a physical "shelter" but it is a space where life occurs. Real architecture has been an answer to our existential need of shelter, creating spaces to shelter our emotions and daily habits. Such architecture was not designed and built according to a pure aesthetic disposition following an "international style", but rather designed according to how the material and structure performed under specific environmental circumstances. Dwellings built had certainly a certain aesthetic, as forms shaped express the need to exist, as an object by itself. Hence, the aesthetics formed due to an existential function, and not a mere economic luxury. Such architectonics resembles the human structure built to perform ultimately in its designated environment, reminding us of the Mound-building Termites ${ }^{9}$. Such habits are not exclusively about the Bekaa area, or the termite ants but rather it is repeatedly done by most organisms in order to coop with the environment and its changes in a sustainable manner.

\section{Conclusions}

As mentioned earlier, aesthetic purity, can be understood in several ways. Architects can interpret it as, honest architecture, pure of any ornaments, or unchanged design. On the other hand, 18th century aesthetic theorist in the philosophical circle represented pure aesthetics as a framed, distanced, and contemplated individual piece to be appreciated. Moreover, in order for an object to be annotated as pure, objects of appreciation must be approached with complete objectivity regardless of its function. Fenner [1] mentions that architecture in that philosophical sense can never be pure, and the system of aesthetic purity is not sound, as architecture, is always related

\footnotetext{
9 Termite structure built by termite ants in a specifically designed architecture to save the eggs and food during winters and summers, making it perform ultimately in its specified environment. The structure of the mounds can be very complicated. Inside the mound is an extensive system of tunnels and conduits that serves as a ventilation system for the underground nest. In order to get good ventilation, the termites will construct several shafts leading down to the cellar located beneath the nest. The mound is built above the subterranean nest. The nest itself is a spheroidal structure consisting of numerous gallery chambers, and they come in a wide variety of shapes and sizes [6].
} 
to function. In order to apprehend architecture purity, we had to look at it from a different perspective, from an etymological, and existential one. Purity in its etymological essence means; simple truth, essence, simple. Connecting it with architecture, we had to look at the essence of architecture or at architecture as an existential phenomenon. As architecture by its essence, is a dwelling space to house our "Throwness" to existence, with all the pain that it comes with. We searched for a dwelling area that can contemplate the requirement of having dwelling spaces and inhabitants not completely adulated by globalization. In our example from Eastern Bekaa Valley, in Lebanon, dwellers created their own designed spaces due to a need, the need to survive and sustain their lives in that specific environment. Environment pushed its inhabitants to design elements from its natural surrounding with the tools they already know. Such space articulations were due to a necessity and not an aesthetic luxury.

This phenomenon of creating spaces out of a need to coop with the surrounding environment gives a glance into new terminology that can be used in architecture and other related domains. The phenomena of creating a space due to a sheer necessity we can call "Phenomenacessity", which is a mixed term of both words "Phenomenon-Necessity". On the other hand, the phenomena of appreciating an element-aesthetic object-created due to a pure necessity to exist, we can call "Phenomenuity", a mix of both words "Phenomenon-Purity". Hence, detach ourselves from the philosophical constrains of pure $a$ priori aesthetic, imposed on aesthetic objects, by tracking it through the existential phenomenon.

\section{References}

[1] Fenner, D. E. 1999. "Pure Architecture in Michael Mitias." In Architecture and Civilization. Amsterdam-Atlanta: Rodopi, 42, 44 \& 56.

[2] Melchert, N. 2011. The Great Conversation: A Historical Introduction to Philosophy. 6th ed. New York: Oxford University Press.

[3] Kant, I. 1855. Critique of Pure Reason. London: Henry G. Bohn, 45.

[4] Heidegger, M. 1971. "Building Dwelling Thinking." In Poetry, Language, Thought. New York: Harper Colophon Books.

[5] Norberg-Schulz, C. 1979. Genius Loci: Towards a Phenomenology of Architecture. New York: Rizzoli, 4.

[6] Dangerfield, J. M., McCarthy, T. S., and Ellery, W. N. 1998. "The Mound-Building Termite Macrotermes michaelseni as an Ecosystem Engineer." Journal of Tropical Ecology 14 (4): 507-20. 